\title{
Influence of Softened Heat-affected Zone on Stress Oriented Hydrogen Induced Cracking of a High Strength Line Pipe Steel
}

\author{
Akihiko TAKAHASHI and Hiroyuki OGAWA ${ }^{1)}$ \\ Yawata R \& D Laboratory, Nippon Steel Corporation, Tobihatacho, Tobata, Kitakyushu, Fukuoka-ken, 804 Japan. \\ 1) Formerly Steel Research Laboratories, Nippon Steel Corporation. Now at Kanazawa Institute of Technology, Oogigaoka, \\ Nonoichi, Ishikawa, Ishikawa-ken, 921 Japan.
}

(Received on April 19, 1995; accepted in final form on May 26, 1995)

\begin{abstract}
The susceptibility to hydrogen induced cracking under applied stress was examined for a large diameter high strength sour service line pipe steel produced by employing the thermo-mechanical control process, i.e. controlled rolling followed by accelerated cooling. The low carbon content aimed at high toughness and weldability resulted in softening in the grain-refined and inter-critical heat-affected zone by thermal cycles of longitudinal sub-merged arc welding. The cracking susceptibility of weldment was transversely evaluated by TM0177-90 method $A$ and compared with the parent metal.

The parent metal indicated high resistance to cracking. Nonetheless, the weldment indicated the decrease in threshold stress, since the weldment ruptured preferably along the softened heat-affected zone. The cracking morphology in the softened heat-affected zone was recognized as stress oriented hydrogen induced cracking. Also performed was a large scale test to reveal the internal incipient cracks in the softened heataffected zone. The observation confirmed that the initiation site was a small cluster of non-metallic inclusions which had probably no adverse effect on the resistance of the parent metal. The stress analysis of the weldment proved that the tension through thickness was generated at mid-thickness under the deformation constraint from surrounding harder parts. The enhanced tri-axiality of stress in company with the through thickness tension facilitates the onset of cracking caused by the hydrogen pressure mechanism. The crack morphology was consistently associated with the stress distribution.
\end{abstract}

KEY WORDS: line pipe; thermo-mechanical control process; hydrogen induced cracking; sulfide stress cracking; heat-affected zone; softening; stress analysis.

\section{Introduction}

Cracking that line pipe steels may encounter in sour environments i.e. hydrogen sulfide containing corrosion environments is generally categorized into three types: hydrogen induced cracking, sulfide stress cracking, stress oriented hydrogen induced cracking. ${ }^{1)}$ Hydrogen induced cracking tends to occur at elongated knife-edge manganese sulfide and at anomalous structures such as segregation streak. ${ }^{2)}$ Sulfide stress cracking predominantly affects steels with a yield strength in excess of $550 \mathrm{MPa}$. Line pipe steels, API grades X65 and lower, do not display sulfide stress cracking in the base metal but the welds in these steels may fail by the cracking because of their higher hardness. ${ }^{3)}$ Stress oriented hydrogen induced cracking, also referred to as type I sulfide stress cracking, appears intermediate between hydrogen induced cracking and sulfide stress cracking in the fracture morphology. ${ }^{4)}$

In order to meet stringent requirements to sour service line pipes latest steel making technology employs calcium treatment, minimizing non-metallic inclusions, soft reduction of continuously cast slabs, and thermomechanical control process i.e. controlled rolling fol- lowed by accelerated cooling. ${ }^{5)}$ The thermo-mechanical control process has the effect of optimizing microstructure to prevent anomalous structure and higher hardness in welds by decreasing carbon content. ${ }^{6}$ However the low content of carbon results in softened heat-affected zone by thermal cycles of welding. Although there has been no reported incident in service relating to softened heat-affected zone, concerns have been raised as a possible cause of cracking in sour environments. ${ }^{7)}$ There are still a number of unclarified points regarding the cracking behavior in the softened heat-affected zone, in particular the role of deformation constraint on the softened region from both the weld metal and the parent metal. The present report therefore aims at evaluating the influence of softening on the susceptibility to cracking at weldment and clarifying the cracking mechanism in the light of the stress distribution.

\section{Experimental}

\subsection{Material}

A high strength steel for sour service conforming to API X65 grade was employed in this study. The chemical 
Table 1. Chemical composition, thickness, and strength of the tested steel. (mass $\%$, *: ppm)

\begin{tabular}{cccccccccccccccc}
\hline Grade & Thickness & $\begin{array}{c}\text { Yield } \\
\text { strength }\end{array}$ & $\mathrm{C}$ & $\mathrm{Si}$ & $\mathrm{Mn}$ & $\mathrm{P}$ & $\mathrm{S} \mathrm{S}^{*}$ & $\mathrm{Ni}$ & $\mathrm{Mo}$ & $\mathrm{Al}$ & $\mathrm{Ti}$ & $\mathrm{Nb}$ & $\mathrm{Ca}^{*}$ & $\mathrm{~N}^{*}$ & $\mathrm{O}^{*}$ \\
\hline $\mathrm{X} 65$ & $28.0 \mathrm{~mm}$ & $513 \mathrm{MPa}$ & 0.051 & 0.25 & 1.14 & 0.005 & 5 & 0.32 & 0.21 & 0.05 & 0.015 & 0.048 & 37 & 17 & 2 \\
\hline
\end{tabular}

composition, thickness and yield strength are summarized in Table 1. The steel was melted in converter, refined with secondary steel processes and continuously cast in the actual production line. In the rolling mill controlled rolling and accelerated cooling was applied to produce heavy plates. Sub-merged arc welding in the laboratory was performed to simulate the longitudinal welding in the large diameter welded pipe mill. The heat input of the sub-merged arc welding was approximately $1.9 \mathrm{MJ} / \mathrm{m}$ for inner surface and $2.7 \mathrm{MJ} / \mathrm{m}$ for outer surface. Vickers hardness distribution was measured on the cross section of the weld. Transverse tensile tests of the weld joint were conducted using a specimen $220 \mathrm{~mm}$ in length, $40 \mathrm{~mm}$ in width, $26 \mathrm{~mm}$ in thickness of the gauge. The weld reinforcement was removed. Also conducted were transverse round bar tensile tests where JIS A2 specimen was employed for the parent metal and the weldment.

\subsection{Sulfide Stress Cracking Test}

Resistance to cracking under stress in the sour environment was evaluated by performing the sulfide stress cracking test in accordance with NACE standard TM0177-90 method A. ${ }^{8)}$ Specimens of the test were machined transversely from the mid-thickness of both the weldment and the parent metal. Threshold stresses of both the weldment and the parent metal were obtained. For the test specimen of weldment, the gauge included the whole weldment from the parent metal to the weld metal positioned at the longitudinal center. In addition, a special type of large scale test was also performed to reveal the initiation of cracking in more detail. The gauge of specimen was $10 \mathrm{~mm}$ in thickness and $400 \mathrm{~mm}$ in length. The specimen was also machined transversely from the mid-thickness of the weldment. The test set-up is shown in Fig. 1. The test procedure was exactly same as that of TM0177-90 method A except for hydraulic loading. After the completion of the large scale test, the specimens were scanned with a high frequency ultrasonic beam of $25 \mathrm{MHz}$ to detect internal incipient cracks. The detected cracks were broken by cooling in liquid nitrogen and observed with a scanning electron microscope.

\section{Results}

\subsection{Softening in the Heat-affected Zone}

Figure 2 shows the Vickers hardness distribution coupled with the macrostructure in the transverse section of weldment. Figure 3 shows the optical microstructures corresponding to labeled points A, B, C in Fig. 2. Maximum hardness is in the weld metal. The hardness decreases in grain-coarsened heat-affected zone (Point A). The location of minimum hardness is along the boundary between grained-refined heat-affected zone

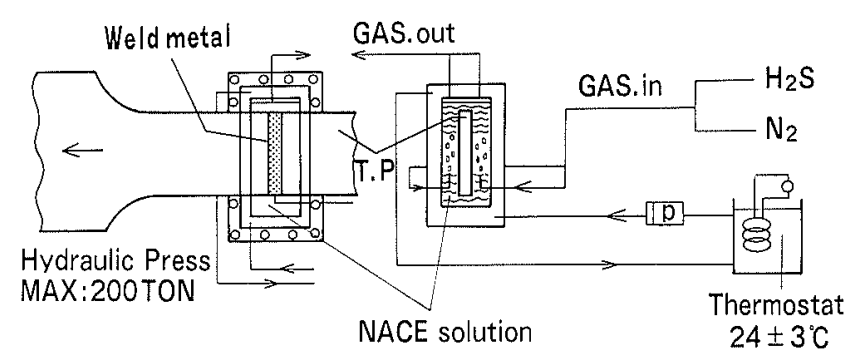

Fig. 1. Test set-up of the large scale sulfide stress cracking test conforming to NACE standard TM0177-90 method A.

(Point B) and inter-critical heat-affected zone where heated to just above and below Ar3 transformation temperature of the steel. In the most softened location, the microstructure consists of mainly fine and homogeneous ferrite grains whereas the microstructure of the parent metal is ferrite and bainite (Point $\mathrm{C}$ ). The microstructure of the parent metal is formed by thermomechanical treatment to provide high strength and superior low temperature toughness. However, the lower content of $\mathrm{C}$ results in soft ferrite due to thermal cycles of welding.

Table 2 summarizes the result of transverse weld joint tensile tests compared with the round bar tensile test of the parent metal. Rupture was within the parent metal as shown in Fig. 4. There was no difference of result between the rectangular tensile test and round bar tensile test as to weldment. Although small decreases in both yield strength and tensile strength of weldment were observed, the weldment has virtually the same strength as the parent metal, in particular for yield strength. Compared to the softening in hardness distribution the influence of softened heat-affected zone of weldment on strength was small in terms of yield strength.

\subsection{Susceptibility to Sulfide Stress Cracking}

Figure 5 shows the relationship between normalized applied stress by yield strength and time to failure of sulfide stress cracking tests including the NACE TM0177-90 method A and the large scale test. The parent metal has such a high cracking/no-cracking threshold stress of 0.95 which reflects micro structural justification by thermo-mechanical control process. Even the steel with high resistance to cracking of this study indicated the clear tendency that the weldment containing local softened heat-affected zone is more susceptible to cracking than parent metal alone. The threshold stress of weldment was 0.8 yield strength. It should be recognized that the threshold stress is still satisfactory enough to meet the common requirement to line pipe steels that no cracking within $720 \mathrm{~h}$ at the applied stress of $72 \%$ specified minimum yield strength is a criteria of acceptance. In addition, it should be paid attention to that the NACE standard test is in good 

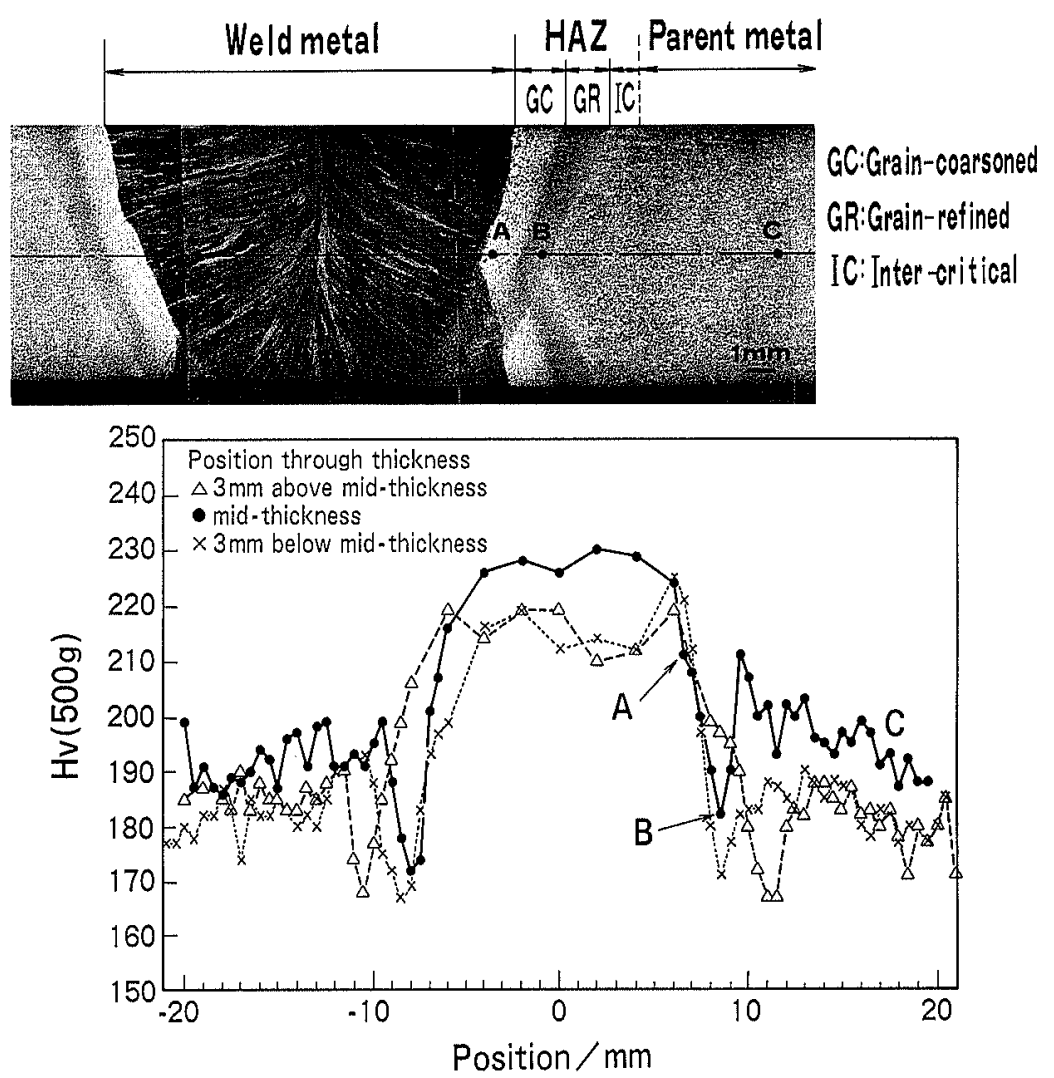

Fig. 2.

Vickers hardness distribution coupled with the macrostructure in the transverse section of weldment.

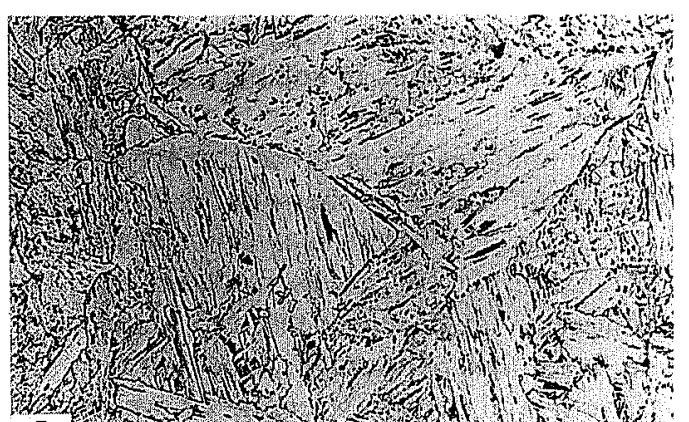

A

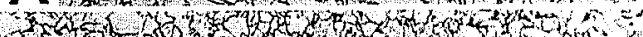

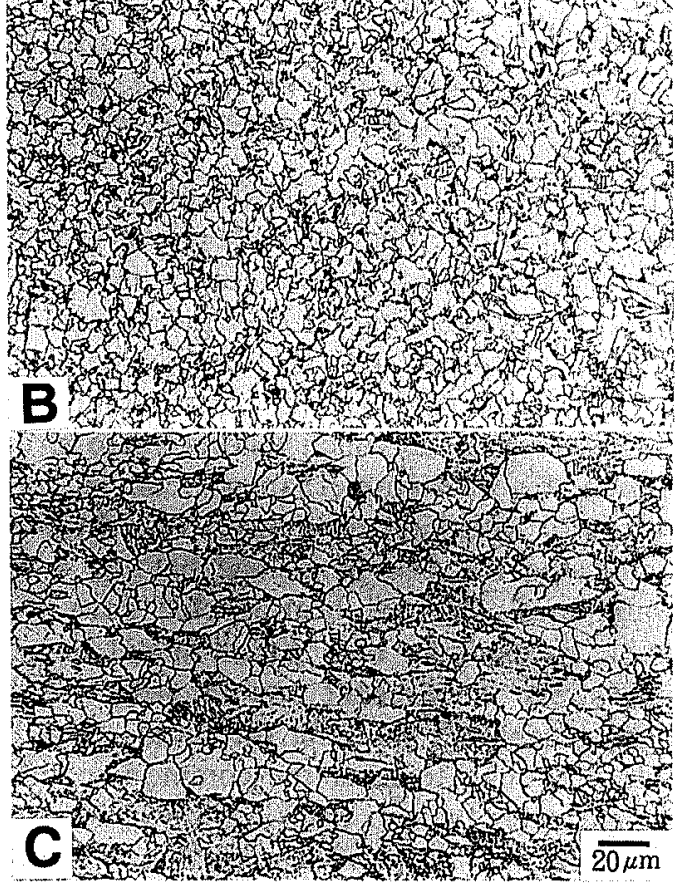

Fig. 3. Optical microstructures corresponding to labeled points A, B, C in Fig. 2.
Table 2. Results of transverse weld joint tensile tests.

\begin{tabular}{llccc}
\hline Tested location & \multicolumn{1}{c}{ Specimen } & $\begin{array}{c}\text { Y.S. } \\
(\mathrm{MPa})\end{array}$ & $\begin{array}{c}\text { T.S. } \\
(\mathrm{MPa})\end{array}$ & $\begin{array}{c}\text { Elongation } \\
(\%)\end{array}$ \\
\hline Parent metal & JISA2 type & 513 & 612 & 26.7 \\
Weld joint & JISA2 type & 505 & 584 & 26.5 \\
Weld joint & Long gauge plate & 505 & 584 & 26.5 \\
\hline
\end{tabular}

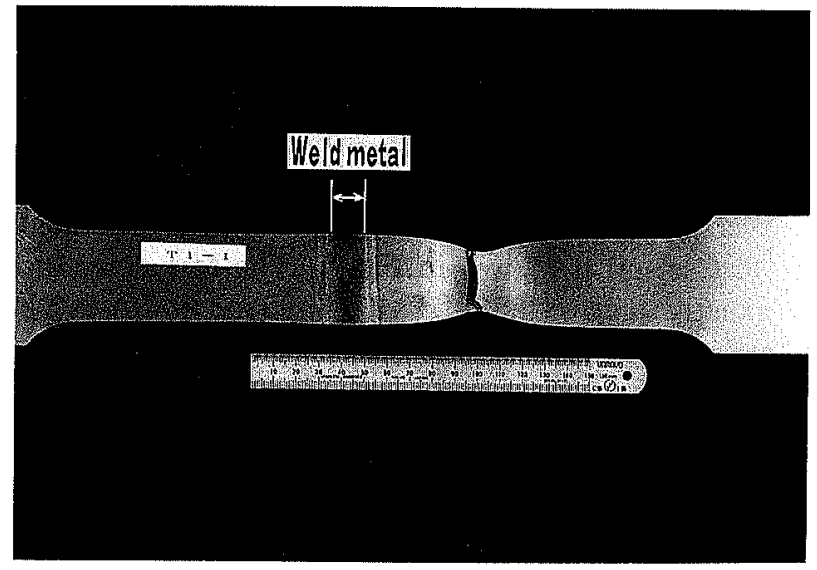

Fig. 4. Ruptured weld joint tensile test plate specimen.

agreement with the large scale test in terms of threshold stress.

Figure 6 shows a longitudinal section of a ruptured NACE standard test specimen for weldment. The rupture was obviously along the most softened heat-affected zone. The rupture was the same way in the large scale test. Ultrasonic examination for large scale specimens of weldment revealed internal cracks which did not lead to fatal rupture under the applied stress less than the threshold stress. Figure 7 indicates the echo image of 
such cracks induced exclusively in the softened heataffected zone. A transverse section of crack is shown in Fig. 8. The incipient cracks were induced parallel to the applied stress. When specimens ruptured under higher stress than the threshold stress, the internal cracks parallel to the applied stress propagated to through thickness direction by linking in the manner of stress oriented hydrogen induced cracking. The observation on the broken crack surface clarified the morphology of hydrogen induced cracking initiated at non-metallic

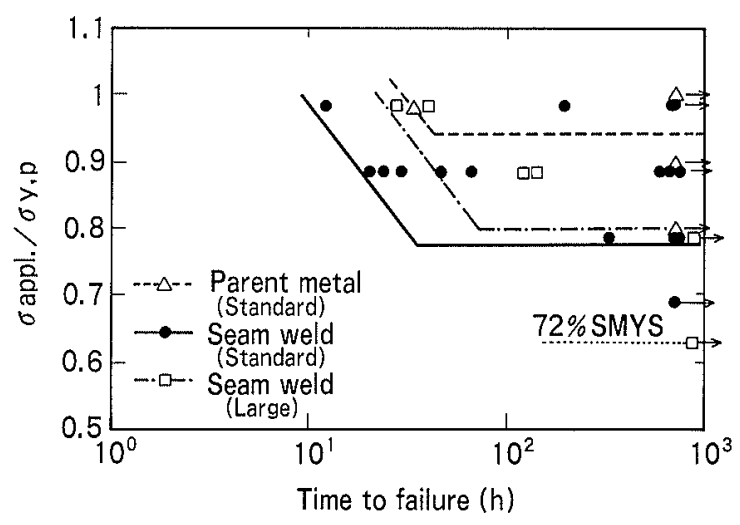

Fig. 5. Relationship between applied stress and time to failure of sulfide stress cracking tests. inclusions as shown in Fig. 9. The initiation site was a cluster of inclusions averaging approximately $20 \mu \mathrm{m}$ in diameter.

\section{Discussion}

In this study it was made clear that hydrogen induced cracking under applied stress was preferably induced in the softened heat-affected zone of weldment. The morphology of the cracking differs from the sulfide stress cracking of high strength steel which is characterized by transverse cracks to applied stress. In the softened heat-affected zone incipient cracks are induced parallel to the applied stress. The incipient cracks link through thickness to rupture. This manner is categorized as stress oriented hydrogen induced cracking. As a matter of fact, the morphology of the crack observed from the view point of fractography was characteristic of the hydrogen induced cracking. It is therefore more justified to term the cracking in the softened heat-affected zone as stress oriented hydrogen induced cracking than sulfide stress cracking. The incipient cracks are induced principally from the blistering mechanism by hydrogen gas pressure. Softened ferrite structure is in favor of yielding in the blistering mechanism. In addition, the linking of incipient cracks are caused by local yielding in slip bands

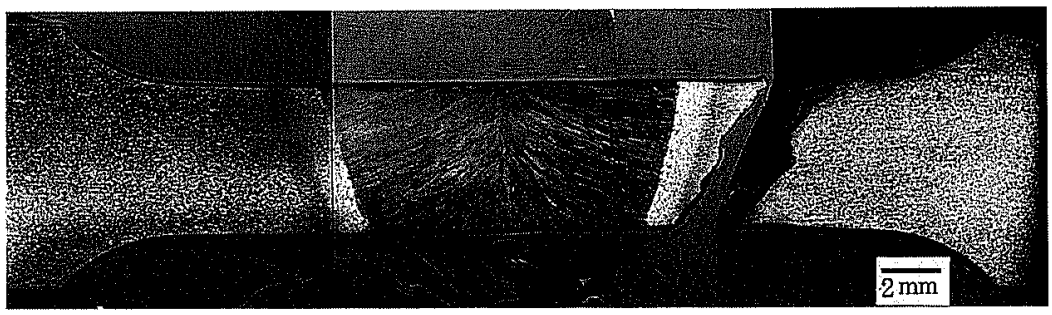

Fig. 6 .

Longitudinal cross section of ruptured round bar sulfide stress cracking test specimen.

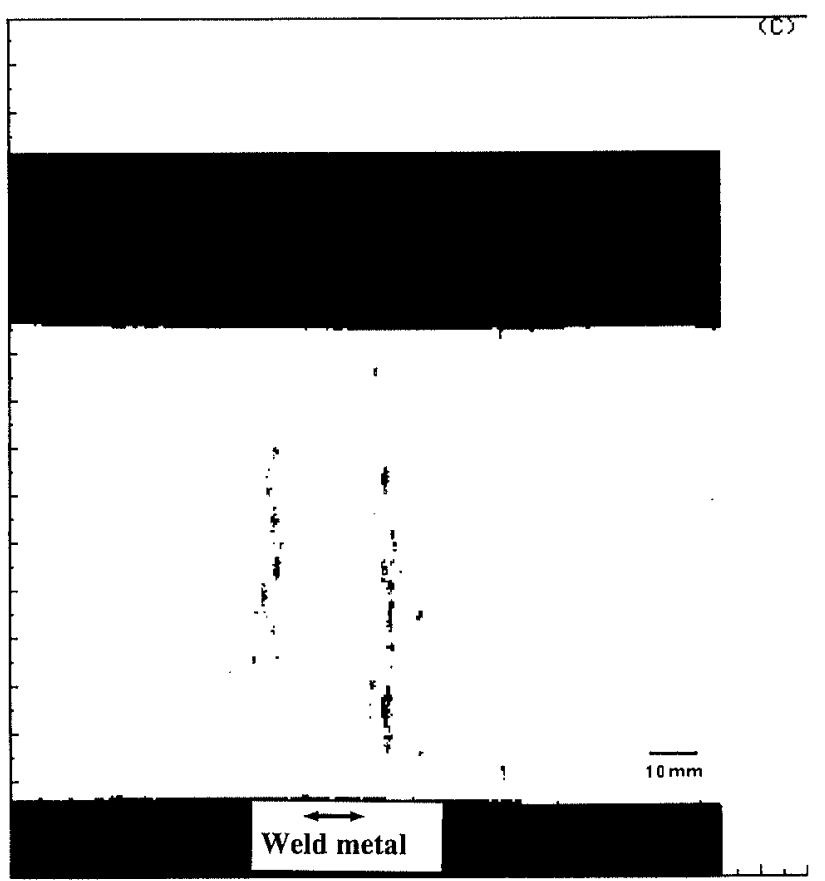

Fig. 7. C scan defect echo image of the internal cracks in the softened heat-affected zone of large scale specimen. The wide side, $100 \mathrm{~mm} \times 100 \mathrm{~mm}$, was scanned with a normal beam of $25 \mathrm{MHz}$.

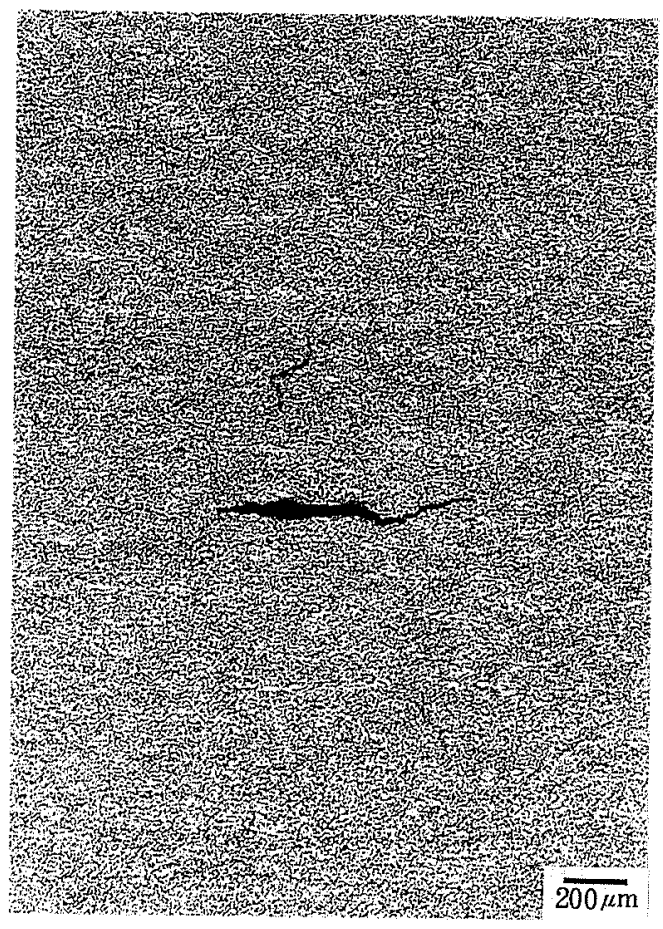

Fig. 8. Transverse section of an internal incipient crack. 
connecting the incipient cracks. ${ }^{9)}$ Softened heat-affected zone hence must facilitate both the initiation and the propagation of cracking. Based on this argument it might be natural to consider that the softened region is susceptible because of minimum yield strength. However the softened region was so small that clear influence of local softening on yield strength was not observed in the weld joint tensile test. It is reported that the small softened region surrounded by harder others is constrained to deform, as a result, has no adverse influence on strength. ${ }^{10)}$

In this context it is worth deliberating what mechanism is dominant under constraint of deformation to understand the role of the small softened region in the stress oriented hydrogen induced cracking of weldment. An elasto-plastic stress analysis was carried out by using the finite element method. The code of FEM was Marc K3 version. Employed was a simple model of the large scale test specimen out of three parts: maximum hardness region (representing weld metal), minimum hardness region (representing softened heat-affected zone), intermediate hardness region (representing parent metal) as demonstrated in the configuration of mesh in Fig. 10. The width of the maximum hardness region and the minimum hardness region roughly simulated the observed result of Fig. 2 and the yield strength was put so that the intermediate hardness region met to the API X65 grade and the minimum hardness region yielded under applied stress to realize the elasto-plastic condition. Elements were of plane strain with eight nodal points. 0.8 yield strength of the parent metal was

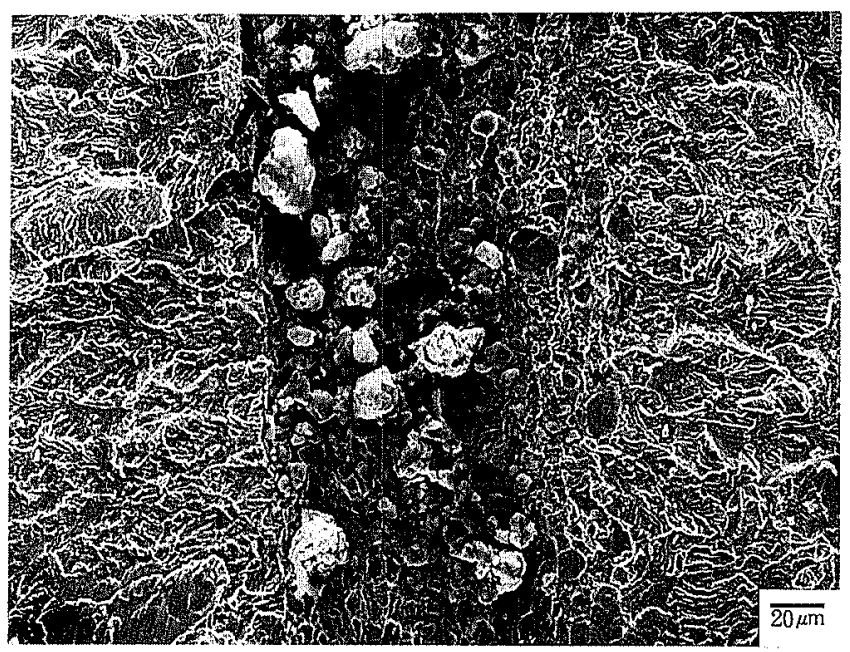

Fig. 9. Crack surface of the internal crack in softened heataffected zone proving hydrogen induced cracking initiated at a cluster of non-metallic inclusions. longitudinally applied, which made the softened part alone yield. Linear work hardening was allowed for the softened part. Figure 11 shows longitudinal and through thickness stress distributions. At first glance, highest stress is recognized around the boundary between the maximum hardness region and the minimum hardness region. From the experiences of sulfide stress cracking, the maximum hardness region where Vickers hardness is above 248 has possible risk of cracking. ${ }^{11)}$ Figure 11 indicates the maximum hardness region adjacent to softened region, namely grain-coarsened heat-affected zone can be most susceptible to cracking. However, this is not the case of steels with low carbon content of which grain-coarsened heat-affected zone has satisfactorily lower hardness than HV 248. On closer examination stress distributions inside the minimum hardness region should be paid attention. Interestingly, the through thickness tension increases at mid-thickness. The minimum hardness region contracts to deform plastically. But the surrounding harder parts are still elastic and constrain the contraction of the minimum hardness region toward mid-thickness. This effect consequently brings about the tension at mid-thickness inside the minimum hardness region. The through thickness tension can collaborate with the internal pressure of intruding hydrogen, also resulting in tension, to form hydrogen induced cracking around mid-thickness. In addition to the through thickness tension, the longitudinal tension is relatively high in the minimum hardness region. Such stress condition leads to high tri-axiality of stress which is favorable to the concentration of intruding hydrogen in the sour environment. The above-mentioned stress analysis is consistent with the observed configuration of incipient cracks in the softened heat-affected zone.

It is well known that knife-edge inclusions such as elongated manganese sulfide by controlled rolling most possibly cause hydrogen induced cracking. In this study the parent metal was virtually resistant to cracking as a consequence of calcium treatment to prevent the formation of knife-edge inclusions. Only initiation site in the softened heat-affected zone was the cluster composed of small lumps of inclusions which is probably harmless to parent metal. The morphology and distribution of such inclusions must be crucial for defining the susceptibility of cracking. From the practical view point of steel making, the control of inclusion configuration regarding the steel examined here reaches the most precise stage. As a matter of fact the parent metal of the steel indicate the high resistance to cracking. This effect is reflected even in the softened heat-affected zone.

WM $\mathrm{HAZ}$

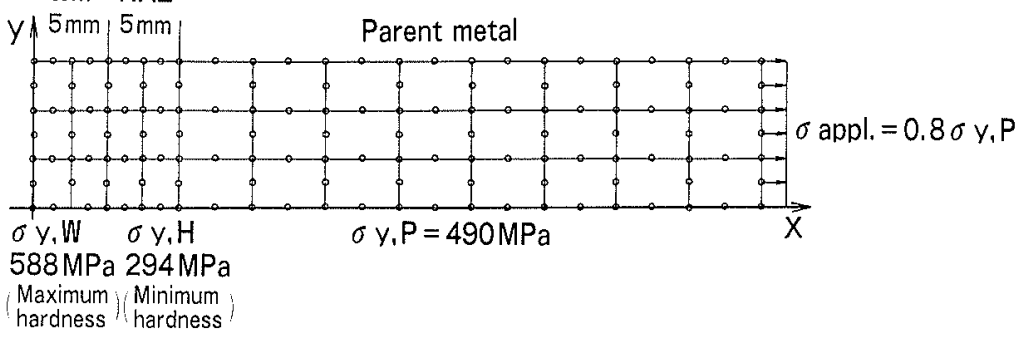

Fig. 10.

FEM model of the large scale test specimen composed of weld metal (W), heat-affected zone $(H)$ and parent metal $(\mathrm{P})$. The assumed yield strengths are $588 \mathrm{MPa}(\mathrm{W}), 294 \mathrm{MPa}(\mathrm{H}), 490 \mathrm{MPa}(\mathrm{P})$. 

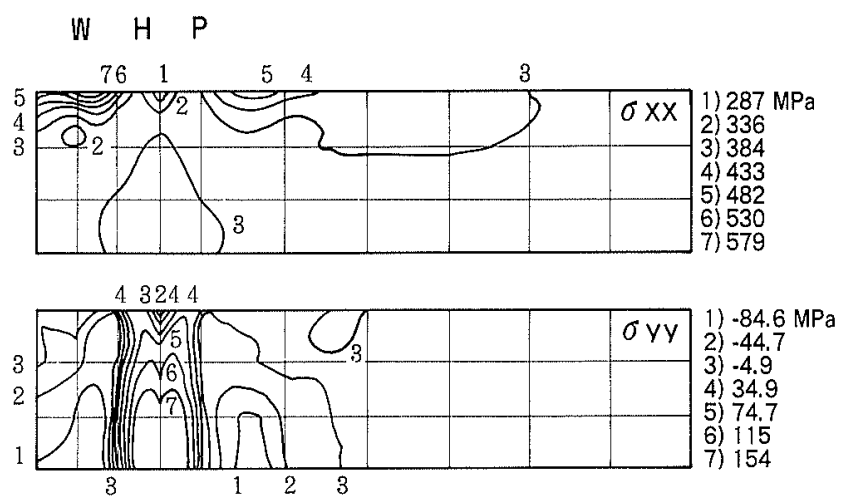

Fig. 11. Stress distribution under the applied stress of 0.8 yield strength of parent metal derived from an FEM analysis.

It should be recognized that the threshold stress is still satisfactorily higher than $72 \%$ specified minimum yield strength after softened weldment has been evaluated.

\section{Summary}

The susceptibility to hydrogen induced cracking under applied stress was examined for a large diameter high strength sour service line pipe steel in an attempt to evaluate the influence of softened heat-affected zone on the development of cracking. The tested line pipe steel was produced by employing the thermo-mechanical control process, i.e. controlled rolling followed by accelerated cooling. Since the carbon content of the steel was low to achieve high toughness and weldability, the grain-refined and inter-critical heat-affected zone, which were heated to just above or below ferrite-austenite transformation temperature, softened after thermal cycles of longitudinal sub-merged arc welding. The cracking susceptibility of the weldment having such softened heat-affected zone was evaluated by TM0177-90 method A and compared with the parent metal. The specimens were machined transversely from the midthickness of the plate wall and the gauge of weldment specimen included the whole weldment from the parent metal to the weld metal positioned at the longitudinal center.

The parent metal indicated high resistance to cracking. Nonetheless, the weldment indicated the decrease in threshold stress as a consequence of the rupture along the softened heat-affected zone. The cracking morphology in the softened heat-affected zone was recognized as stress oriented hydrogen induced cracking, in which manner longitudinal incipient cracks oriented parallel to the applied stress linked in the direction of thickness to propagate.

Also performed was a large scale test to clarify the initiation of the internal incipient cracks in the softened heat-affected zone. The fracture surface observation confirmed that the initiation site was a small cluster of non-metallic inclusions which had probably no adverse effect on the resistance of parent metal.

The stress analysis of the weldment assuming the yielding of the softened heat-affected zone proved that the tension through thickness was generated at midthickness under the deformation constraint from surrounding harder parts. The enhanced tri-axiality of stress in company with the through thickness tension facilitates the onset of cracking caused by the hydrogen pressure mechanism. The morphology of stress oriented hydrogen induced cracking was consistently associated with the stress distribution.

\section{REFERENCES}

1) B. D. Craig: Practical Oil Field Metallurgy and Corrosion, Pennwell Books, Tulsa, Oklahoma, (1992), 212.

2) H. Tamehiro, T. Yoshino, N. Yurioka and M. Abe: Proc. 8th Int. Conf. on Ofshore Mechanics and Arctic Engineering (OMAE), Vol. 5, The Hague, The Netherlands, (1989), 339.

3) H. Tamehiro, Y. Horii, M. Yamaguchi, Y. Ogata, H. Akasaki, Y. Kawada, H. Miyazaki, K. Shinada and H. Ogawa: Proc. 10th Int. Conf. on Offshore Mechanics and Arctic Engineering (OMAE), Vol. 5, Stavanger, Norway, (1991), 85.

4) T. Kaneko, M. Takeyama, M. Nakanishi, Y. Sumitomo and A. Ikeda: NACE Middle East Corrosion Conference, Bahrain, (1979), 932

5) H. Chino, M. Abe, K. Katayama, H. Tamehiro and H. Akasaki: Proc. Pipeline Technology Conf., The Royal Flemish Soc. of Engineers, Östende, Belgium, (1990), 4.1.

6) H. Tamehiro, T. Takeda, S. Matsuda, K. Yamamoto and N. Okumura: Trans. Iron Steel Inst. Jpn., 25 (1985), 982.

7) NACE Task Group T-1F-23: Mater. Perform., January, (1993), 58.

8) NACE standard TM0177-90, (1990).

9) M. Iino: Metall. Trans., 9A (1978), 1581.

10) Y. Onoe, H. Morikawa, Y. Sogo and K. Nakajima: TMS-AIME Annual Meeting, Atlanta, GA, (1983), 1. 